\title{
Serum 25-Hydroxyvitamin D Levels of Apparently Healthy Nigerian Children Aged 1-24 Months
}

\author{
Akeredolu FD ${ }^{1^{*}}$, Akuse $\mathrm{RM}^{2}$, Mado $S M^{2}$ and Yusuf $\mathrm{R}^{3}$ \\ ${ }^{1}$ Department of Paediatrics, Federal Medical Centre, Gusau, Zamfara State, Nigeria \\ ${ }^{2}$ Department of Paediatrics, Ahmadu Bello University Teaching Hospital, Zaria, Kaduna State, Nigeria
}

${ }^{3}$ Department of Chemical Pathology, Ahmadu Bello University Teaching Hospital, Zaria, Kaduna State, Nigeria

*Corresponding author: Dr. Akeredolu Festus Dele, Department of Paediatrics, Federal Medical Centre, Gusau, Zamfara state, Nigeria, Tel: +2348052425491

\begin{abstract}
Introduction: The role of vitamin D in promoting health and contributing to disease is an emerging area of research interest that has important health care and public health implications. As the health relevance of vitamin $\mathrm{D}$ outside bone health is now being explored globally, scanty data is available about the vitamin D status of healthy Nigerian children. Because Infants and young children have a relatively low supply of foods rich in vitamin $D$ and may also have inadequate exposure to sunlight, they are at risk of vitamin $D$ deficiency. We measured and described 25-hydroxyvitamin $D$ levels of apparently healthy young Nigerian children.
\end{abstract}

Subjects and methods: This was a cross sectional, descriptive study involving 112 apparently healthy children living in Zaria, North-West Nigeria which has adequate sunshine all through the year. Serum $25(\mathrm{OH}) \mathrm{D}$ concentrations were determined using a vitamin D ELISA kit. A level above $75 \mathrm{nmol} / \mathrm{l}$ was used to define vitamin D sufficiency in accordance with the Endocrine Society recommendations.

Results: The mean 25-Hydroxyvitamin D level was 58.6 $\pm 30.5 \mathrm{nmol} / \mathrm{l}$ (range: $6.5-146 \mathrm{nmol} / \mathrm{l})$. Only $31(27.7 \%)$ of the children had 25-hydroxyvitamin D levels above $75 \mathrm{nmo-}$ $\mathrm{I} / \mathrm{I}$, while $35(31.3 \%)$ had insufficient $(50-75 \mathrm{nmol} / \mathrm{l})$ and 46 $(41.0 \%)$ had deficient (<50 nmol/l) serum vitamin $D$ levels. There was no significant difference with regard to sex, age, nutritional and socioeconomical status between the groups.

Conclusion: Apparently healthy young Northern Nigerian children had high prevalence of 25 -hydroxyvitamin $D$ insufficiency and deficiency. It is recommended that population studies be carried out across Nigeria to define the 25-hydroxyvitamin D levels of Nigerian children and establish predictors or determinants of vitamin D levels in them. This will assist in the development of governmental policies and strategies to prevent, detect, and treat vitamin $D$ deficiency in Nigeria.

\section{Keywords}

Vitamin D, 25-hydroxyvitamin D, Young children, Nigeria

\section{Introduction}

Vitamin $D$ is essential for maintaining bone health in children and adults and its deficiency is an established cause of nutritional rickets and osteomalacia. More recently, vitamin $\mathrm{D}$ is proposed to have extra-skeletal activities including protecting against many chronic conditions like autoimmune diseases, diabetes, cardiovascular diseases, and cancer [1-7]. It may also facilitate the ability of immune cells to defend against infections like respiratory tract infections including pneumonia [8-12]. The health relevance of vitamin $D$ outside bone health is now being explored globally and it is speculated that vitamin D may have a role to play in the management of the new coronavirus disease (Covid-19) [11-14].

Cutaneous synthesis is the most important source of vitamin $D$ from sunlight. Nutritional sources become important in the absence of sunlight [15]. Breast milk has a low vitamin D content (approximately 12-60 IU/L) even in a mother with sufficient vitamin $D[15,16]$. Animal products constitute the bulk source of vitamin $D$ that occurs naturally in unfortified foods. Liver, organ meats, fatty fish such as herring, salmon, sardines, tuna, mackerel, and fish liver oils are good sources of vitamin D [15-17].

Serum or plasma 25 -Hydroxy Cholecalciferol $(25(\mathrm{OH})$ D) is the most commonly used and appropriate bio-

Citation: Akeredolu FD, Akuse RM, Mado SM, Yusuf R (2021) Serum 25-Hydroxyvitamin D Levels of Apparently Healthy Nigerian Children Aged 1-24 Months. Int J Pediatr Res 7:076. doi.org/10.23937/24695769/1510076

Accepted: July 21, 2021: Published: July 23, 2021

Copyright: (c) 2021 Akeredolu FD, et al. This is an open-access article distributed under the terms of the Creative Commons Attribution License, which permits unrestricted use, distribution, and reproduction in any medium, provided the original author and source are credited. 
chemical marker of vitamin D status $[15,18]$. There is no absolute consensus on the definition of normal or healthy 25-hydroxyvitamin D levels. While The Institute of Medicine of the United States National Academies [19] defined vitamin D deficiency as serum 25(OH)D concentrations $<12 \mathrm{ng} / \mathrm{ml}(<30 \mathrm{nmol} / \mathrm{l})$, insufficiency as serum $25(\mathrm{OH}) \mathrm{D}$ concentrations from $12-20 \mathrm{ng} / \mathrm{ml}$ (30$50 \mathrm{nmol} / \mathrm{l}$ ) and sufficiency as serum 25(OH)D concentrations $>20 \mathrm{ng} / \mathrm{ml}$ (>50 nmol/l), some researchers have argued that this concentration may not be sufficient to confer the extra-skeletal benefits of vitamin D. Thus a higher serum 25(OH)D concentration between 50 and $125 \mathrm{nmol} / \mathrm{l}$ was proposed to be adequate [20-23].

Vitamin D deficiency or insufficiency is a global health problem and its prevalence varies from one country or region to another because of difference in risk factors [2427]. Although there is abundant sunshine all through the year in Nigeria, the practice of inadequate sun exposure for cultural, religious or personal reasons (staying in door, excessive clothing when outdoors) might put infants and young toddlers at high risk of hypovitaminosis D. Other factors like maternal vitamin D deficiency during pregnancy, exclusive breastfeeding, consumption of family diet with low vitamin $D[16,28]$, may predispose to hypovitaminosis $D$ in children. Most foods that are naturally rich in vitamin $D$ are not easily affordable as part of weaning foods for young Nigerian children.

Little is known about vitamin D status of apparently healthy Nigerian children. A study done over twenty years ago by Pfitzner, et al. [29] reported that there was no vitamin D deficiency in young Nigerian children (aged 6-35 months); whereas three other studies done later which involved Newborns [30] older children [31] and adolescents [32] reported subnormal 25-hydroxyvitamin D levels.

In order to prevent vitamin $D$ deficiency in breast feeding infants, vitamin D supplementation of $400 \mathrm{IU} /$ day is recommended $[28,33]$. This recommendation may be appropriate in temperate climates but this may not be necessary in Nigeria because of its abundant sunshine all the year round. Hence, data on vitamin D status of Nigerian young children is needed for decision making as whether to adopt or reject this recommendation.

This study described the levels of 25-hydroxyvitamin D levels in apparently healthy young Nigerian children. We hope that this study will contribute to the body of evidence in defining the vitamin $D$ status of Nigerian children. This will also be relevant in formulating appropriate national and local policies and strategies aimed at reducing hypovitaminosis $D$ and its related diseases among children in Nigeria.

\section{Subjects and Methods}

\section{Study location}

This study was carried out in the Department of Paediatrics of Ahmadu Bello University Teaching
Hospital (ABUTH), Zaria. The city is located in the NorthWestern Nigeria on latitude $11.09^{\circ} \mathrm{N}$ and longitude $7.72^{\circ} \mathrm{E}[34,35]$ and it receives abundant sunshine (average of 7 to 8 hours per day) [35] all through the year. ABUTH is a multi-specialty health care provider which provides both secondary and tertiary care to the people of Kaduna state and its environs.

\section{Ethical clearance}

Approval was obtained from the Human Research and Ethical Committee of ABUTH, Zaria. A written informed consent was obtained from parents/guardians before enrollment of children into the study.

\section{Study design}

The study was part of a larger prospective cross sectional comparative study conducted over a 12-month period from August 2015 to July 2016 in order to determine association between vitamin $D$ status and acute pneumonia. The data of apparently healthy children aged 1 to 24 months were extracted and reported.

\section{Subjects}

The subjects were 112 apparently healthy children (with no known chronic medical conditions like HIV, sickle cell anaemia, severe malnutrition etc.) aged 1-24 months who were brought for immunization, minor surgery (such as circumcision and herniorrhaphy) or who accompanied sick siblings; and whose parents consented to participate. All the participants were living in Zaria and its environs which have abundant sunshine all the year round. Children who were taking drugs known to affect vitamin D metabolism (such as phenytoin, phenobarbitone, carbamazepine, clotrimazole, rifampicin and dexamethasone) or who had received vitamin $D$ supplements or cod liver oil in the six weeks preceding enrollment into the study were excluded.

\section{Sample collection}

A structured interviewer-administered questionnaire was used to obtain relevant information about the recruited children. Socio-economic index scores were awarded to each child based on the occupations and educational attainment of the parents or their substitutes using Oyedeji's classification [36]. Detailed Physical and systemic examinations were carried out on each child. The measured weight and length/height were plotted on the WHO growth chart to determine the nutritional status of the child using the $Z$ score cutoff points defined by WHO [37].

Three milliliters of peripheral venous blood was collected from each of the recruited children into a plain tube and allowed to clot at room temperature. The clotted blood sample was then centrifuged and the serum separated into another plain tube using a Pasteur 
pipette. The serum was transported on dry ice packs to the chemical pathology laboratory of ABUTH, Zaria where samples were stored at $-20^{\circ} \mathrm{C}$ until analysis.

Serum 25(OH)D (vitamin D) was assayed using commercial vitamin D ELISA kit \{AccuDiag $^{\mathrm{TM}} 25-\mathrm{OH}$ Vitamin D (total) ELISA Kit, Diagnostic Automation/ Cortes Diagnostics Inc., Woodland Hills, USA\} [38]. The kit has a range of assay between $2.89-130 \mathrm{ng} / \mathrm{ml}$; specificity of antibodies: $25-\mathrm{OH}$ Vitamin D3 - 100\%, 25-OH Vitamin D2 - 74\%, 1,25 -OH Vitamin D3 < 0.1\%; sensitivity - $<2.98 \mathrm{ng} / \mathrm{ml}$; Intra assay variability (CV) of $3.0-6.6 \%$ and interassay variability (CV) of $8.6-10 \%$.

\section{Data analysis}

Data was analyzed using SPSS (version 20: IBM Corporation). We determined the prevalence for each vitamin D groups: Deficiency (serum 25(OH)D concentration $<50 \mathrm{nmol} / \mathrm{l}$ ), insufficiency (serum $25(\mathrm{OH}$ ) D concentration 50-75 nmol/l), and sufficiency (serum $25(\mathrm{OH}) \mathrm{D}$ concentration $>75 \mathrm{nmol} / \mathrm{l}$ ) as recommended by Endocrine Society [23]. Any relationship between 25-hydroxyvitamin $D$ levels and the determinant variable was tested using appropriate statistical tools. A $p$ value of less than 0.05 was considered statistically significant.

\section{Results}

A total number of 112 children aged 1-24 months were studied, consisting 72 (64.3\%) males and 40
(35.7\%) females with mean age $10.8 \pm 6.8$ months.

\section{Vitamin D status of participants}

The mean 25 -Hydroxyvitamin D level was $58.6 \pm 30.5$ $\mathrm{nmol} / \mathrm{l}$ with the range between 6.5 and $146 \mathrm{nmol} / \mathrm{l}$. Only $31(27.7 \%)$ of the children had 25-hydroxyvitamin D levels above $75 \mathrm{nmol} / \mathrm{l}$ (Vitamin D sufficiency) while 35 (31.3\%) and $46(41.0 \%)$ children had vitamin D insufficiency and deficiency respectively (Table 1 ).

\section{Predictors of 25-Hydroxyvitamin D Levels}

Table 2 shows that the mean 25-hydroxyvitamin D levels for males and females were similar $(p=0.977)$. Children in the first 6 months had the lowest mean serum 25-hydroxyvitamin $D$ level compared to others; this was not statistically significant $(p=0.094)$.

Nutritional status appeared to predict 25-hydroxyvitamin D levels; the mean $25-\mathrm{OH}$ vitamin D levels followed a decreasing pattern from underweight, through normal weight to overweight $(p=0.730)$.

Children with high socioeconomic class parents had highest mean 25-hydroxyvitamin $D$ level while those with low socioeconomic class parents had the lowest. This difference was not statistically significant $(p=$ $0.284)$.

Serum 25(OH)D was dichotomized into normal vitamin D group(serum 25(OH)D level above $75 \mathrm{nmol} / \mathrm{l}$ ) and low vitamin D group (serum 25(OH)D level of

Table 1: Distribution of children according to vitamin D status.

\begin{tabular}{|l|l|l|}
\hline Serum 25(OH)D level & No of children $\mathbf{( N = 1 1 2 )}$ & Percentage (\%) \\
\hline Deficiency $(<50 \mathrm{nmol} / \mathrm{l})$ & 46 & 41.0 \\
\hline Insufficiency $(50-75 \mathrm{nmol} / \mathrm{l})$ & 35 & 31.3 \\
\hline Sufficiency $(>75 \mathrm{nmol} / \mathrm{l})$ & 31 & 27.7 \\
\hline Total & 112 & 100 \\
\hline
\end{tabular}

Table 2: Mean Serum 25-Hyroxyvitamin D Levels according to sex, age group, nutritional and socioeconomic status.

\begin{tabular}{|l|l|l|l|l|}
\hline Variable & Frequency (\%) & Mean serum 25(OH)D nmol/I & Test statistics & t $=-0.028$ \\
\hline Sex & & & & \\
\hline Male & $72(64.3)$ & $58.6 \pm 30.4$ & \\
\hline Female & $40(35.7)$ & $58.8 \pm 30.9$ & F $=2.183$ \\
\hline Total & $112(100)$ & & \\
\hline Age group & & $49.1 \pm 30.7$ & \\
\hline $1-6$ months & $37(33.0)$ & $62.1 \pm 33.5$ & \\
\hline $7-12$ months & $38(33.9)$ & $60.6 \pm 21.5$ & \\
\hline $13-18$ months & $20(17.9)$ & $69.5 \pm 29.2$ & \\
\hline $19-24$ months & $17(15.2)$ & & F $=0.316$ \\
\hline Total & $112(100)$ & & \\
\hline Nutritional status & & $58.8 \pm 31.8$ & \\
\hline Normal weight & $84(75.0)$ & $59.5 \pm 25.3$ & \\
\hline Under weight & $26(23.2)$ & $41.8 \pm 30.5$ & \\
\hline Overweight & $02(1.8)$ & & \\
\hline Total & $112(100)$ & & \\
\hline
\end{tabular}




\begin{tabular}{|l|l|l|l|l|}
\hline Socioeconomic status & & & F $=1.273$ & 0.284 \\
\hline High (Classes 1 \& 11) & $38(33.9)$ & $65.0 \pm 27.2$ & \\
\hline Middle (Class 111) & $51(45.6)$ & $55.8 \pm 34.6$ & \\
\hline Low (Classes 1V \& V) & $23(20.5)$ & $54.4 \pm 24.8$ & \\
\hline Total & $112(100)$ & & \\
\hline
\end{tabular}

F: ANOVA; t: Independent samples T-test

Table 3: Association between sex, age, nutritional, socioeconomical and vitamin D status.

\begin{tabular}{|c|c|c|c|c|c|}
\hline Variable & Normal vitamin D level $n=31$ & Low vitamin D level $n=81$ & Total & Test statistics & $P$ value \\
\hline Sex & & & & $x^{2}=0.001$ & 0.975 \\
\hline Male & $20(64.5 \%)$ & $52(64.2 \%)$ & $72(64.3 \%)$ & & \\
\hline Female & $11(35.5 \%)$ & $29(35.8 \%)$ & $40(35.7 \%)$ & & \\
\hline Total & $31(100 \%)$ & $81(100 \%)$ & $112(100 \%)$ & & \\
\hline Age group & & & & $x^{2}=4.710$ & 0.194 \\
\hline 1-6 months & $07(22.6 \%)$ & $30(37.1 \%)$ & $37(33.0 \%)$ & & \\
\hline 7-12 months & $11(35.5 \%)$ & $27(33.3 \%)$ & $38(33.9 \%)$ & & \\
\hline $13-18$ months & $05(16.1 \%)$ & $15(18.5 \%)$ & $20(17.9 \%)$ & & \\
\hline 19-24 months & $08(25.8 \%)$ & $09(11.1 \%)$ & $17(15.2 \%)$ & & \\
\hline Total & $31(100 \%)$ & $81(100 \%)$ & $112(100 \%)$ & & \\
\hline Nutritional status & & & & $x^{2}=0.509$ & 0.775 \\
\hline Normal weight & $23(74.2 \%)$ & $61(75.3 \%)$ & $84(75.0 \%)$ & & \\
\hline Under weight & $07(22.6 \%)$ & $19(23.5 \%)$ & $26(23.2 \%)$ & & \\
\hline Overweight & $01(03.2 \%)$ & $01(01.2 \%)$ & $02(1.8 \%)$ & & \\
\hline Total & $31(100 \%)$ & $81(100 \%)$ & $112(100 \%)$ & & \\
\hline $\begin{array}{l}\text { Socioeconomic } \\
\text { status }\end{array}$ & & & & $x^{2}=0.440$ & 0.803 \\
\hline High (Classes 1 \& 11) & $12(38.7 \%)$ & $26(32.1 \%)$ & $38(33.9 \%)$ & & \\
\hline Middle (Class 111) & $13(41.9 \%)$ & $38(46.9 \%)$ & $51(45.5 \%)$ & & \\
\hline Low (Classes 1V \& V) & $06(19.4 \%)$ & $17(21.0 \%)$ & $23(20.6 \%)$ & & \\
\hline Total & $31(100 \%)$ & $81(100 \%)$ & $112(100 \%)$ & & \\
\hline
\end{tabular}

$X^{2}=$ Pearson Chi-Square

$75 \mathrm{nmol} / \mathrm{l}$ or less). We compared the children with low vitamin $D$ level against those that had normal vitamin $D$ level with regard to sex, age, nutritional and socioeconomical status. There was no statistically significant difference between the two groups (Table 3 ).

\section{Discussion}

This study described the 25-hydroxyvitamin D levels in apparently healthy young Nigerian children aged 1-24 months. Based on the 25-hydroxyvitamin D levels more than 7 out of every 10 children had a low level of 25-hydroxyvitamin D while less than 3 out of every 10 children were vitamin D sufficient.

These findings are quite important as it appears that, despite the location of Nigeria and the intensity of UV rays it receives throughout the year, Nigerian children have insufficient levels of vitamin D. Pfitzner, et al. [29] had earlier reported over two decades ago, that vitamin $D$ deficiency was absent in young Nigerian children (aged 6-35 months) living in Jos, North-Central Nigeria. However, they used a lower cut off point of $10 \mathrm{ng} / \mathrm{ml}$
$(25 \mathrm{nmol} / \mathrm{I})$ to define normal 25 -hydroxyvitamin D levels at that time compared to the cut off points recently proposed by the Endocrine Society of below $50 \mathrm{nmol} / \mathrm{l}$ for deficiency and 50-75 $\mathrm{nmol} / \mathrm{l}$ for insufficiency. We reported a slightly lower mean of $58.6 \pm 30.5 \mathrm{nmol} / \mathrm{l}$ than their own report of $66.8 \pm 24.2 \mathrm{nmol} / \mathrm{l}$, but both means were in the category of vitamin $D$ insufficiency. Also, more than half of the children studied by Pfitzner, et al. had serum $25(\mathrm{OH}) \mathrm{D}$ below $30 \mathrm{ng} / \mathrm{ml}(75 \mathrm{nmol} / \mathrm{l})$ this would have been classified as insufficiency vitamin $D$ level now based on the recent classification.

Vitamin D deficiency and insufficiency is a global health problem and the prevalence varies across countries and subpopulations depending on the risk factors and the serum 25(OH)D cut off points used. Using a cut-off serum level of less than $50 \mathrm{nmol} / \mathrm{l}$, we reported a low vitamin D prevalence of $41 \%$. This is lower compared to findings from studies on 25-hydroxyvitamin D among young children from Iran (66.7\%, cut-off of less than $50 \mathrm{nmol} / \mathrm{L}$ ) [24], Mexico (54\% cut-off of less than $50 \mathrm{nmol} / \mathrm{L}$ ) [25], Saudi Arabia (58.8\%, cut-off of less than 
$50 \mathrm{nmol} / \mathrm{L}$ ) [26] and USA (63\%, cut-off of less than 75 $\mathrm{nmol} / \mathrm{L})$ [27].

The reasons for the high prevalence of low vitamin $D$ levels in these children is not clear but some speculations that need further research may be proffered. The Northern region of Nigeria is predominantly Muslims and the use of hijab is a common practice among mothers. They usually back their infants and young toddlers covered with their hijab whenever they are going out. Also, some of the women are usually in door with their young children as they are not gainfully employed or doing some petty trading at home. These practices may interfere with adequate exposure of these infants and young toddlers to sunlight and may put them at risk of low vitamin $\mathrm{D}$ status.

To the best of our knowledge, this is the first published work on serum 25-hydroxyvitamin $D$ levels among apparently healthy young children living in the North-West region of Nigeria and one of the few studies on this subject from Sub-Saharan Africa. The implication of our findings is that that population studies need to be carried out across the country to define the 25-hydroxyvitamin D levels of Nigerian children and establish predictors or determinants of vitamin $D$ levels in them. However, health professionals, policy makers, and the general public in Nigeria should be aware of the possibility of a high prevalence of vitamin $D$ deficiency and insufficiency despite the abundant sunshine in Nigeria. Also, given the growing understanding of established associations of vitamin $D$ status and the incidence of some disease conditions like respiratory tracts infections, autoimmune disorders, etc. $[4,6,8,12]$ efforts to reduce the burden of diseases in Nigeria should also incorporate strategies to prevent, detect, and treat hypovitaminosis $\mathrm{D}$.

Our study is not without limitations. We did not evaluate for effects of seasons, sunlight exposure practices and diets; as our goal was not to verify the causes or predictors of low levels of 25-hydroxyvitamin $D$, but rather to describe the 25-hydroxyvitamin $D$ levels in these apparently healthy children. Although we only included studies with healthy participants in this hospital-based study, population-based studies are better at inferring the 25 -hydroxyvitamin $D$ levels of the general population.

In conclusion, despite the location of Nigeria and the intensity of UV rays it receives throughout the year, apparently healthy young Northern Nigerian children had a high prevalence of 25 -hydroxyvitamin $D$ insufficiency and deficiency. It is recommended that population studies be carried out across the country to define the 25-hydroxyvitamin D levels of Nigerian children and establish predictors or determinants of vitamin D levels in them. These will assist in the development of governmental policies and strategies to prevent, detect, and treat vitamin $\mathrm{D}$ deficiency in
Nigeria.

\section{References}

1. Lin R, White $\mathrm{JH}$ (2004) The pleiotropic actions of vitamin D. Bioessays 26: 21-28.

2. Holick MF (2004) Vitamin D: Importance in the prevention of cancers, type 1 diabetes, heart disease, and osteoporosis. Am J Clin Nutr 79: 362-371.

3. Reis AF, Hauache OM, Velho G (2005) Vitamin D endocrine system and the genetic susceptibility to diabetes, obesity and vascular disease. A review of evidence. Diabetes Metab 31: 318-325.

4. McGrath J (2001) Does 'imprinting' with low prenatal vitamin $\mathrm{D}$ contribute to the risk of various adult disorders? Med Hypotheses 56: 367-371.

5. Marino R, Misra M (2019) Extra-skeletal effects of vitamin D. Nutrients 11: 1460.

6. Papandreou D, Malindretos P, Karabouta Z, Rousso I (2010) Possible health implications and low vitamin D status during childhood and adolescence: An updated mini review. Int J Endocrinol 2010: 472173.

7. Zipitis CS, Akobeng AK (2008) Vitamin D supplementation in early childhood and risk of type 1 diabetes: A systematic review and meta-analysis. Arch Dis Child 93: 512-517.

8. Walker VP, Modlin RL (2009) The Vitamin D connection to pediatric infections and immune function. Pediatr Res 65: 106R-113R.

9. Prentice A, Schoenmakers I, Jones KS, Jarjou LMA, Goldberg GR (2009) Vitamin D deficiency and its health consequences in Africa. Clinic Rev Bone Miner Metab 7: 94-106.

10. Wayse V, Yousafzai A, Mogale K, Filteau S (2004) Association of subclinical vitamin $D$ deficiency with severe acute lower respiratory infection in Indian children under 5 years. Eur J Clin Nutr 58: 563-567.

11. Weir EK, Thenappan T, Bhargava M, Chen Y (2020) Does vitamin D deficiency increase the severity of COVID-19? Clin Med 20: e107-e108.

12. Murdaca G, Pioggia G, Negrini S (2020) Vitamin D and Covid-19: An update on evidence and potential therapeutic implications. Clin Mol Allergy 18: 23.

13. Jain A, Chaurasia R, Sengar NS, Singh M, Mahor S, et al. (2020) Analysis of vitamin D level among asymptomatic and critically ill COVID-19 patients and its correlation with inflammatory markers. Scientific Reports 10: 20191.

14. Griffin G, Hewison M, Hopkin J, Kenny R, Quinton R, et al. (2020) Vitamin D and COVID-19: Evidence and recommendations for supplementation. R Soc Open Sci 7: 201912.

15. Greenbaum LA (2012) Rickets and hypervitaminosis D. In: Nelson Textbook of Paediatrics. Kleigman RM, Behrman RE, Stanton BF, Saunder, Philadelphia, 200-209.

16. Green RJ, Samy G, Miqdady MS, El-Hodhod M, Akinyinka OO, et al. (2015) Vitamin D deficiency and insufficiency in Africa and the Middle East, despite year-round sunny days. S Afr Med J 105: 603-605.

17. Vitamin D (2011) [cited 23/03/2014]; Available from: http:// vitamind.ucr.edu/about/.

18. Mantecon L, Alonso MA, Moya V, Andres AG, Avello N, et al. (2018) Marker of vitamin D status in healthy children: Free or total 25-hydroxyvitamin D? PLoS One 13: e0202237. 
19. Ross AC, Taylor CL, Yaktine AL, Valle HBD (2011) Dietary reference intakes for calcium and Vitamin $D$. Institute of Medicine, National Academies Press, Washington, DC, 3-14.

20. Espositol S, Lelli M (2015) Vitamin D and respiratory tract infections in childhood. BMC Infectiuos Diseases 15: 487.

21. Holick MF, Binkley NC, Bischoff-Ferrari HA, Gordon CM, Hanley DA, et al. (2012) Guidelines for preventing and treating vitamin $D$ deficiency and insufficiency revisited. J Clin Endocrinol Metab 97: 1153-1158.

22. Lips $P$ (2007) Vitamin D status and nutrition in Europe and Asia. J Steroid Biochem Mol Biol 103: 620-625.

23. Holick MF, Binkley NC, Bischoff-Ferrari HA, Gordon CM, Hanley DA, et al. (2011) Evaluation, treatment and prevention of vitamin $D$ deficiency: An Endocrine Society clinical practice guideline. J Clin Endocrinol Metab 96: 1911-1930.

24. Motlaghzadeh $Y$, Sayarifard F, Allahverdi B, Rabbani A, Setoodeh $A$, et al. Assessment of vitamin $D$ status and response to vitamin D3 in obese and non-obese iranian children. J Trop Pediatr 62: 269-275.

25. Brito A, Cori H, Olivares M, Mujica MF, Cediel G, et al. (2013) Less than adequate vitamin $D$ status and intake in Latin America and the Caribbean: A problem of unknown magnitude. Food Nutr Bull 34: 52-64.

26. Mansour MMHK, Alhadidi KM (2012) Vitamin D deficiency in children living in Jeddah, Saudi Arabia. Indian J Endocrinol Metabo 16: 263-269.

27. Mansbach JM, Ginde AA, Camargo Jr CA (2009) Serum 25-Hydroxyvitamin $D$ levels among US children aged 1 to 11 years: Do children need more vitamin D. Pediatrics 124 : 1404-1410.
28. Fink C, Peters RL, Koplin JJ, Brown J, Allen KJ (2019) Factors affecting vitamin D status in infants. Children 6: 7.

29. Pfitzner MA, Thacher TD, Pettifor JM, Zoakah Al, Lawson $\mathrm{JO}$, et al. (1998) Absence of vitamin D deficiency in young Nigerian children. J Pediatr 133: 740-744.

30. Owie E, Afolabi BB (2018) Vitamin D deficiency in pregnant women and newborns in Lagos, Nigeria. J Obstet Gynaecol 38: 616-621.

31. Adegoke SA (2017) Prevalence and factors influencing sub-optimal serum levels of 25-hydroxyvitamin D among children with sickle cell anaemia in southwest Nigeria. Annals of Health Research 3: 118-125.

32. Godwill OC, Hamilton O (2012) 25-Hydroxycholecalciferol levels in a representative sample of children and young adolescents from the Ikwerre-speaking Local Government Areas of Rivers State, Nigeria. Journal of Dental and Medical Sciences 1: 47-52.

33. Cediel G, Pacheco-Acosta J, Castillo-Durán C (2018) Vitamin D deficiency in pediatric clinical practice. Arch Argent Pediatr 116: e75-e81.

34. (2020) Where is Zaria, Nigeria on Map?

35. WorldData.info. Climate for Kaduna (Nigeria).

36. Oyedeji GA (1985) Socioeconomic and cultural background of hospitalized children in llesha. Nig J Paediatr 12: 111117.

37. World Health Organisation (2017) Global database on child growth and malnutrition: Cut-off points and summary statistics.

38. (2015) Diagnostic Automation/Cortez Diagnostic Inc.

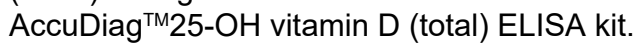

